\title{
SNOW AND ICE FEEDBACK AND CLIMATE SENSITIVITY
}

\section{(Abstract)}

by

\section{Alan Robock}

(Department of Meteorology, University of Maryland, College Park, Maryland 20742, U.S.A.)

A new parameterization of snow and ice area and albedo is presented, based on recent satellite observations of snow and ice extent (Robock 1980, 1983). This parameterization is incorporated into a seasonal energy-balance $\mathrm{cl}$ imate model. Experiments are conducted with the model to determine the effects of this parameterization on the latitudinal and seasonal distribution of model sensitivity to external forcings of climate change (solar constant variations and volcanic dust) and to internally forced $\mathrm{cl}$ imate change.

The snow/ice area and snow/ice mel twater feedbacks are found to determine the sensitivity pattern to external forcing, producing enhanced sensitivity in the polar regions in the winter and decreased sensitivity in the polar regions in the summer. This result holds for both equilibrium experiments, where a step function forcing is applied at the beginning of the simulation and the model is run to equilibrium (Robock 1983), and for transient experiments where the forcing is time-dependent (Robock 1981). This pattern is produced by the sea-ice thermal inertial feedback. Snow and ice albedo feedbacks are relatively weak.

This response pattern is the same as that found by Manabe and Stouffer (1980) with a general circulation model. The enhanced sensitivity in the summer found by Ramanathan and others (1979) is shown to be due to a surface albedo feedback parameterization which does not allow the thermal inertia to change.

The sensitivity to internal forcing is amplified by the snow/ice feedback, producing a higher variance of the resulting temperature time series. The spectra of the series are shifted to more variance in the lower frequencies. The latitudinal and seasonal pattern of variance shows higher variance at higher latitudes due to the lower mean thermal inertia, but the pattern is relatively unaffected by the presence or absence of snow/ice feedbacks because the mean thermal inertia does not change.

\section{ACKNOWLEDGEMENT}

This work has been supported by US National Science Foundation grants ATM-7918215 and ATM- 8213194 .

\section{REFERENCES}

Manabe S, Stouffer R J 1980 Sensitivity of a global cl imate model to an increase of $\mathrm{CO}_{2}$ concentration in the atmosphere. Joumal of Geophysical Research 85(C10): 5529-5554

Ramanathan V, Lian M S, Cess R D 1979 Increased atmospheric $\mathrm{CO}_{2}$ : zonal and seasonal estimates of the effect on the radiation energy balance and surface temperature. Jourmal of Geophysical Research 84(C8): 4949-4958

Robock A 1980 The seasonal cycle of snow cover, sea ice and surface albedo. Monthly Weather Review 108(3): 267-285

Robock A 1981 The Mount St. Helens volcanic eruption of 18 May 1980: minimal climatic effect. Science 212: $1383-1384$

Robock A 1983 Ice and snow feedbacks and the latitudinal and seasonal distribution of climate sensitivity. Jourmal of the Atmospheric Seiences 40: 986-997

\section{MODELING THE LATE-QUATERNARY GLACIAL}

\section{VARIATIONS WITH MULTI-COMPONENT}

\section{CLIMATIC SYSTEMS}

\author{
(Abstract) \\ by

\section{B. Saltzman} \\ (Department of Geology and Geophysics, Yale University, New Haven, Connecticut O6511, U.S.A.) \\ Because of the small net rates of energy flow in- \\ volved in very long-term changes in ice volume \\ $\left(10^{-1} \mathrm{~W} \mathrm{~m}^{-2}\right)$ it will be impossible to proceed in a \\ purely deductive manner to develop a theory for these \\ changes. An inductive approach will be necessary en- \\ tailing the formulation of multi-component stochastic- \\ dynamical systems of equations governing the variables \\ and feedbacks thought to be relevant from qualitative \\ physical reasoning (e.g. "conceptual models"). The \\ output of such models should be required to conform \\ as closely as possible to all lines of observational \\ evidence on climatic change and, in addition, should \\ have a predictive quality in the search for new ob- \\ servational evidence. Moreover, the models themselves \\ should be required to satisfy the general conservation \\ laws and all the results of physical measurement of \\ the fast response (high energy flow) processes in the \\ system that generally lead to diagnostic relation-
}

